\title{
perifèria
}

Número 15, diciembre 2011

www.periferia.name

\section{Identidades Politizadas no Reconhecimento Jurídico da Diferença: uma reflexão sobre o caso dos quilombos no Brasil ${ }^{1}$}

\author{
Rebeca Campos Ferreira ${ }^{2}$ \\ Universidade de São Paulo, USP, Brasil
}

\section{Resumo:}

A realidade das comunidades remanescentes de quilombo no Brasil, sujeitos políticos que emergem a partir do Artigo 68 do ADCT/CF-88, permite pensar a política da identidade no acesso a direitos, no contexto do reconhecimento da diferença e do pluralismo jurídico. Trata-se da possibilidade de acesso a um direito de caráter coletivo, étnico e territorial, que remete à construção identitária, na medida em que o preceito constitucional pressupõe a emergência da identidade quilombola, em que pese a ressemantização do conceito, para fins da aplicabilidade legal. As prerrogativas constitucionais colocam o foco em marcadores étnicos e constituem paradoxo, no que tange à generalidade da lei frente às singularidades das situações, e ainda à fluidez de conceitos entre usos analíticos e nativos. A reflexão volta-se, portanto, à orientação política da identidade a partir do caso dos quilombos.

Palavras-chave: Comunidades Remanescentes de Quilombos, Identidades, Etnicidade, Direitos Sociais, Marcadores Étnicos.

\footnotetext{
1 Trabalho apresentado Congresso de Antropologia Universitat Autônoma de Barcelona e Universidade de São Paulo, Jornadas UAB-USP 2011: A Antropologia transatlântica do século XXI: novas perspectivas, ocorrido entre os dias 20 e 21 de outubro em São Paulo e Barcelona. Agradeço aos importantes comentários de Montserrat Ventura i Oller (UAB), aos professores Márcio Ferreira da Silva e Vagner Gonçalves da Silva (USP), à María Carballo (UAB) e às Comissões Editoriais das revistas Periferia (UAB) e Cadernos de Campo (USP).

2 Doutoranda do Programa de Pós Graduação em Antropologia Social da Universidade de São Paulo, PPGAS - USP. Bolsista da Fundação de Amparo à Pesquisa do Estado de São Paulo, FAPESP. Pesquisadora do Núcleo de Antropologia do Direito, NADIR - USP. Correio eletrônico: rebeca.ferreira@usp.br
} 


\title{
perifèria
}

Número 15, diciembre 2011

www.periferia.name

\section{Resumen:}

La realidad de los remanentes de quilombos en Brasil, los sujetos políticos que emergen del artículo 68 de ADCT/CF-88, nos permite considerar las políticas de identidad en el acceso a los derechosen el contexto del reconocimiento de la diferencia y del pluralismo jurídico. Es la posibilidad de acceder a un derecho colectivo, étnico y de la tierra, lo que se refiere a la construcción de la identidad, en la medida en que la disposición constitucional que supone la emergencia la identidad quilombola, a pesar de la reconceptualización del concepto de Quilombo, por aplicabilidad de la ley. Las prerrogativas constitucionales pone el foco en los marcadores étnicos, y constituyen la paradoja, con respecto a la generalidad de la ley, en comparación con las singularidades de las situaciones, y también la fluidez de los conceptos entre los usos nativos y analíticos. Por lo tanto, este artículo reflexiona sobre la orientación política de la identidad, desde el caso de los quilombos en Brasil.

Palabras clave: remanentes de las comunidades quilombolas, identidades, minorías étnicas, los derechos sociales, marcadores étnicos.

\begin{abstract}
:
The reality of the remnants of Quilombo communities in Brazil, political subjects that emerge from Article 68 of ADCT/CF-88, allows us to consider the politics of identity in access to rights in the context of recognition of difference and legal pluralism. It is the possibility of access to a collective right, ethnic and agrarian, which refers to the construction of identity, insofar as the constitutional provision presupposes the emergence of quilombola identity, despite the reconceptualization of the concept of Quilombo, for applicability of the law. The constitutional prerogatives pose the focus on ethnic markers and constitute paradox regarding the generality of the law, compared to the singularities of the situations, and also the fluidity of concepts between native and analytical uses. therefore, this article reflects on the political orientation of identity, from the case of quilombos in Brazil.
\end{abstract}

Keywords: Remnants

of Quilombo Communities,

Identities, Ethnicity, Social Rights, Ethnic Markers. 


\section{perifèria}

Número 15, diciembre 2011

www.periferia.name

\section{Apresentação}

O presente ensaio reflete sobre etnicidades, a partir da emergência da identidade quilombola no contexto do reconhecimento de direitos diferenciados às comunidades remanescentes de quilombos, no âmbito do prescrito pelo Artigo 68 do Ato das Disposições Constitucionais Transitórias da Constituição Brasileira de 1988. Volta-se à possibilidade de acesso a um direito de caráter coletivo, étnico e fundiário, que remete à construção identitária, na medida em que o preceito constitucional pressupõe a emergência da identidade em questão, em que pese a ressemantização do conceito de quilombo, para fins da aplicabilidade legal.

A partir do caso dos remanescentes pode-se então pensar acerca das etnicidades, identidades e culturas que permeiam a discussão acerca do reconhecimento de direitos diferenciados a determinados grupos - os direitos culturais e seus desdobramentos - considerando que se trata, sobretudo, de um reconhecimento realizado pelo Estado, onde a lei cria seu sujeito, embora se observem os princípios da auto adscrição.Em questão se coloca o fato de que marcadores étnicos - fluidos e carregados de singularidades - representam o acesso a direitos - genéricos - a diversos grupos historicamente destituídos dos mesmos, na esteira do reconhecimento jurídico da diferença e do multiculturalismo. O caso dos remanescentes de quilombos, sujeitos instituídos, servirá à reflexão ora proposta, dos momentos onde o recurso a identidade étnica se torna bandeira de luta; coloca-se em questão as orientações políticas da etnicidade, a politização da diferença.

\section{Notas sobre a reconceitualização do conceito de quilombo}

Atribuir identidade quilombola a determinado grupo e dar-lhe direitos fundiários levanta a questão do redimensionamento do próprio conceito de quilombo. No momento em que o Estado reconhece um grupo como remanescente de quilombo 


\section{perifèria}

Número 15, diciembre 2011

www.periferia.name

fixa uma identidade não só política, administrativa e legal, mas também identidade social, permitindo assim direito à uma identificação étnica, que é veículo de obtenção de direitos diferenciados. Desse modo, o artigo 68 do Ato das Disposições Constitucionais Transitórias da Constituição Federal de 1988 instituiu um novo sujeito social, um novo sujeito político etnicamente diferenciado a partir dos direitos instituídos por meio do artigo citado.

Tal disposição do Estado em institucionalizar a categoría evidencia a tentativa de reconhecimento formal de uma transformação social considerada como incompleta. A institucionalização incide sobre resíduos e sobrevivências, revelando as distorções sociais de um processo de abolição da escravatura limitado, parcial (ALMEIDA, 1997: 125).

Com isso, portanto, vem à tona a necessidade de redimensionar o conceito de quilombo, que "deixa de ser considerado unicamente como categoria histórica ou definição jurídica formal para se transformar, nas mãos de centenas de comunidades rurais e urbanas em instrumentos de luta pelo reconhecimento de direitos territoriais" (TRECCANI, 2006: 14), de modo que possa abranger a variedade de situações de ocupação de terras por grupos remanescentes, para além da noção de fuga e de resistência.

A conversão simbólica do conceito de quilombo engendrada a partir do preceito legal cria então novo sujeito, no contexto de lutas sociais que fazem da lei o seu instrumento; o quilombo é metamorfoseado e ganha funções políticas, como instrumento de luta pela terra. Desse modo, cria-se, como o Artigo 68, a categoria remanescente de quilombo, e institui este como sujeito de direitos fundiários e direitos culturais ${ }^{3}$ (ARRUTI, 2003). E na medida em que a condição de remanescente de quilombo abarca elementos de identidade e sentimento de

3 Vale ressaltar que os formuladores da lei não previam os efeitos criadores da mesma, visto que no momento da discussão o pensamento se voltava ao passado, e não ao futuro; o objeto da lei não antecede o seu projeto, e assim o direito cria seu próprio sujeito, e o artigo em questão acaba por criar, portanto, categoria política e sociológica. (ARRUTI, 2003). 


\section{perifèria}

Número 15, diciembre 2011

www.periferia.name

pertença a um grupo e à terras determinadas, entram no debate sobre o conceito de quilombo considerações acerca da etnicidade e da territorialidade ${ }^{4}$.

O conceito é cercado por inúmeras referências, e a aplicação do Artigo 68 gerara demandas quanto à definição do termo, na medida em que novas figuras legais, novos sujeitos de direito, penetram o direito positivo "através dessas rachaduras hermenêuticas que são os direitos difusos" (ARRUTI, 1997: 01). Ressemantizar o conceito de quilombo fez-se então necessário para discernir critérios de identificação das comunidades remanescentes, tanto no plano conceitual quanto no plano normativo, agindo, portanto, em universos de referência distintos, o da análise científica e de intervenção jurídica.

O conceito de quilombo fora fortemente disseminado na década de 1970, reapropriado pelo Movimento Negro como símbolo da Resistência Negra, física e cultural, estruturado não só na forma de grupos fugidos durante a escravidão, mas também na forma ampla de quaisquer grupos tolerados pela ordem dominante do período (NASCIMENTO, 1981). O quilombismo concretiza-se então na década de 1980, e o ano do centenário da abolição, 1988, coincide com o ano da promulgação da carta constitucional. O conceito é, portanto, cercado por inúmeras referências, e a aplicação do Artigo 68 gerara demandas quanto à definição do termo.

Em 1740, o Conselho Ultramarino definiu quilombo como "toda habitação de negros fugidos, que passem de cinco, em parte despovoada, ainda que não tenham ranchos levantados e nem se achem pilões nele" (SCHIMITT, TURATTI \& CARVALHO, 2002:02). Nesse ponto, vale ressaltar brevemente a crítica de Alfredo Wagner de Almeida (1999), que aponta como bases dessa definição noções de fuga, isolamento geográfico, com moradia habitual, o "rancho", e auto consumo e reprodução, simbolizados pelo "pilão", bem como uma quantidade mínima. Assim, a existência do quilombo pressupõe independência, indica que a produção é

\footnotetext{
4 Schmitt, Turatti e Carvalho (2002) consideram que estes dois conceitos, identidade étnica e territorialidade, são fundamentais e estão sempre inter-relacionados no caso das comunidades negras rurais.
} 


\section{perifèria}

Número 15, diciembre 2011

www.periferia.name

autônoma e livre da influência do senhor da terra, engendrando ainda relações com o comércio local.

A caracterização do Conselho Ultramarino influenciara geração de estudiosos do assunto até meados da década de 1970 (RAMOS, 1953; CARNEIRO, 1957), período no qual a literatura quilombola aparece marcada com atribuições a um tempo histórico passado, cristalizado na vigência do regime escravocrata brasileiro e caracterizado como negação deste sistema, como resistência e isolamento somente. São, portanto, trabalhos que não abarcam a diversidade de relações engendradas entre escravos e sociedade livre, tampouco consideram as distintas formas de ocupação e uso da terra.

Carlos Magno Guimarães (1995: 75/79) constata que quilombos "configuram (e estão no centro de) uma realidade conflituosa da qual participam diferentes senão todas - categorias sociais". Para esse autor, a questão é identificar o modo pelo qual se dá a participação de cada categoria social, o posicionamento político, no contexto do conflito que atinge a sociedade. Toma o quilombo como "modalidade de existência do campesinato na sociedade escravista colonial", ressaltando a necessidade de perceber esse campesinato em sua dimensão econômica e política, enquanto "agente coletivo no jogo das contradições que dão tônica à dinâmica social"; o quilombo é como fenômeno, e principalmente como projeto político.

Em suma, o conceito de quilombo fora submetido a inúmeras reapropriações simbólicas, até que ganhara, com a definição da Associação Brasileira de Antropologia, em 1994, uma interpretação que se tornou dominante, a partir da nova significação que the era dada pela literatura específica e por entidades civis. Tomou-se então remanescentes de quilombo como "grupos que desenvolveram práticas de resistência na manutenção e reprodução de seus modos de vida característicos num determinado lugar", e a identidade como "uma referência histórica comum, construída a partir de vivências e valores partilhados". Remanescentes de quilombos formam então grupos étnicos, "tipo organizacional que confere pertencimento através de normas e meios empregados para indicar afiliação ou exclusão", onde o tanto o uso comum caracteriza a territoriedade 


\section{perifèria}

Número 15, diciembre 2011

www.periferia.name

quanto a "sazonalidade das atividades agrícolas, extrativistas e outras", e a ocupação do espaço tem "por base os laços de parentesco e vizinhança, assentados em relações de solidariedade e reciprocidade" (ARRUTI, 2003: 23).

Vale ainda destacar que a formação destes territórios é mediada por uma pluralidade de formas de acesso e usufruto, construído coletivamente e moldado por uma memória e por práticas culturais peculiares a cada situação. A Fundação Cultural Palmares toma quilombos como "sítios historicamente ocupados por negros que tenham resíduos arqueológicos de sua presença, inclusive as áreas ocupadas ainda hoje por seus descendentes, com conteúdos etnográficos e culturais".

Passa então do "Modelo Palmares", vinculado à idéia de resistência, contra aculturação, reprodução do mundo africano, luta de classes, autonomia e isolamento, às situações concretas e documentadas, fazendo uso de manuscritos e de fontes orais. A noção de remanescente é reconhecida como dispositivo constitucional que dá sentido de existência coletiva, sendo categoria temporal, visto que é situacional, é contingencial (ALMEIDA \& PEREIRA, 2003: 231)

Por um lado, a identificação de comunidades rurais negras que ganham o estatuto de unidades culturais e sociais por partilharem uma origem e uma cosmologia comuns, uma ancestralidade, por apresentarem grandes índices de endogamia e por vezes até mesmo um dialeto particular, escorregando assim para o pólo do isolamento, da alteridade, do exotismo, do universo de referências autônomo e original. Por outro, ganham visibilidade política e acadêmica (...) a partir de uma identidade genérica, de caboclos já assimilados, sem língua distinta, cristianizados, integrados ao mercado local e nacional como força de trabalho móvel, escorregando, dessa forma, para o pólo da interação, do universo político e cognitivo partilhado (ARRUTI, 1997: 11).

A ressemantização do termo quilombo caminha no sentido da afirmação de sua contemporaneidade, na linha da existência de uma identidade coletiva, com referência histórica comum e valores compartilhados. As propostas vão a um novo reconhecimento, evitando dar-Ihe significação que reproduza repressão ou que the idealize; toma então situações sociais específicas, com finalidades de garantia da terras e afirmação de identidade própria.

Ressemantizar o quilombo é, portanto, abandonar sentidos que Ihe são dados por meio da legislação colonial, deixar o simbolismo que o cerca, que lhe é dado tanto 


\section{perifèria}

Número 15, diciembre 2011

www.periferia.name

pela literatura acadêmica - sobretudo da década de 1970, influenciada pelo marxismo - quanto por movimentos negros; é deslocar o conceito de sua significação simbólica original, que apresenta uma mescla com confronto com emergência de identidade. A caracterização do quilombo como expressão da negação do sistema escravocrata, como lócus da resistência e isolamento dá lugar às novas definições, tendo em vista que as clássicas oposições não abarcam todas as dimensões da sociedade escravista, tampouco do contexto da emergência dos remanescentes no Brasil democrático.

\section{A Emergência dos Remanescentes de Quilombos}

No âmbito da luta pelo reconhecimento dos direitos, os remanescentes de quilombos exemplificam o modo pelo qual a diferença é politizada, indo além da esteira jurídica que dá origem à categoria. Enquanto sujeitos permitem pensar os desdobramentos das políticas da identidade, quando a etnicidade ganha orientação política e se torna bandeira de luta. E no contexto dessas lutas o que se tem são reconfigurações das próprias construções identitárias, negociações e articulações.

Costa (2006: 134) aponta para a:

disseminação crescente de grupos diversos voltados para a reconstrução de raízes culturais e étnicas obliteradas pala vigência do discurso homogeneizador da mestiçagem. Trata-se aqui, entre outros, dos processos de reconstrução de etnicidades indígenas, entre os descentes de imigrantes e da invenção de uma etnicidade quilombola.

O movimento em questão seria estético e cultural, voltado à ressignificação e reinterpretação do lugar conferido ao negro na sociedade e na cultura nacional e global e, ao mesmo tempo, um movimento político voltado ao combate do racismo ${ }^{5}$. São processos que representam uma inflexão quando se toma o discurso

\footnotetext{
5 Nesse sentido, pode-se aproximar ao que fora apontado por Stuart Hall referente ao curso de formação de novas etnicidades negras no Reino Unido.
} 


\section{perifèria}

Número 15, diciembre 2011

www.periferia.name

da mestiçagem e da democracia racial. O que se tem é a emergência de novas formas de representação da nação (COSTA, 2006), que podem aqui ser pensadas pelo caso dos remanescentes de quilombos. As novas etnicidades negras inseremse, portanto, na discussão voltada à politização da diferença, com o acréscimo de ser esta uma diferença respaldada por direitos diferenciados e constitucionalmente assegurados. E nesse contexto, as categorias raça, etnicidade e cultura vão então oscilar entre usos políticos, nativos e analíticos.

Sobre os usos da cultura vale ser posto que "no uso popular, a distinção criteriosa que os cientistas sociais vem tentando estabelecer entre cultura, etnia e raça desaparecem por completo. Essas categorias tornam-se fluidas e intercambiáveis" (SANSONE, 2007: 15/16). E no processo de reconhecimento de comunidades remanescentes de quilombos a 'cultura negra' é pressuposta pelos órgãos envolvidos e recriada no âmbito do grupo. Enquanto para Mintz a cultura negra é mista e sincrética, para Sansone (2007: 23):

a cultura negra pode ser definida como a subcultura específica das pessoas de origem africana dentro de um sistema social que enfatize a cor, ou a ascendência a partir da cor, como critério importante de diferenciação ou segregação das pessoas. (...) para não torná-la mais estática, convém considerar a cultura negra como uma subcultura da cultura ocidental, muitas vezes quase submergida na cultura popular (...) ela não é fixa nem completamente abrangente e resulta de um conjunto específico de relações sociais.

Acerca dessas considerações, Miguel Vale de Almeida (2009: 01) desenvolve a idéia de essencialismo estratégico, no que se refere aos movimentos sociais de caráter identitário, que são postos frente ao dilema de "por um lado recusarem os próprios termos da categorização de que são alvo e, por outro, necessitarem de identificação com as categorias, de modo a poderem movimentar-se no espaço público". Arruti (1997: 14) desenvolve proposições acerca da emergência de remanescentes, no sentido de rearranjos classificatórios, na medida em que, as unidades de descrição das populações submetidas respondem, ao custo de uma brutal redução de sua alteridade, às necessidades de produção de unidades 


\section{perifèria}

Número 15, diciembre 2011

www.periferia.name

genéricas de intervenção e controle social, sendo que tais unidades variam segundo aquelas necessidades de controle e domínio.

O surgimento de comunidades remanescentes corresponde, portanto, à produção de novos sujeitos políticos, "novas unidades de ação social através de uma maximização da alteridade que, por um lado, subverte a indistinção e por outro intensifica a comparabilidade" (ARRUTI, 1997: 19). O conceito remanescente surge como a solução classificatória, "para resolver a difícil relação de continuidade e descontinuidade com o passado histórico, em que a descendência não parece ser um laço suficiente" (ARRUTI, 1997: 21). Vale ainda colocar que o termo "não era conhecido ou usado pelos remanescentes até que lhes fosse comunicado" (ARRUTI, 1997, 23). Tem-se então um processo - conflituoso - de nomeação de um grupo enquanto remanescente, que produz uma série de mudanças nas próprias comunidades, nas suas relações internas e externas, seja com populações vizinhas, poderes locais ou aparelhos do Estado, bem como entre seus próprios membros, com acomodações, disputas, conflitos, alterações de significados atribuídos às festas e rituais, reelaboração da memória e alteração do status de seus pares.

O reconhecimento jurídico de comunidades como remanescentes de quilombos e portadoras de direitos implica em transformações e negociações em diversos âmbitos, alterando relações internas, mudando tanto a auto percepção das comunidades quanto a percepção de grupos não remanescentes frente àqueles. A identificação e o reconhecimento oficial são, portanto, parte de um amplo processo de produção, a saber: produção de limites e fronteiras, produção de memórias, produção de nova rede de relações, produção de novos sujeitos políticos, produção de revisão histórica e sociológica e ampliação de hermenêutica jurídica. A produção de novas redes de relação é tomada em conjunto com a produção de novos sujeitos políticos, este que não são somente camponeses ou trabalhadores rurais, nem são somente negros. Esses novos sujeitos então instituem-se como categoria específica, engendrando novo tipo de relações sociais. Passam a ter sentimento de 


\section{perifèria}

Número 15, diciembre 2011

www.periferia.name

unidade sócio-cultural e sua força política cresce junto com a força social e os direitos que adquirem (ARRUTI, 2003: 41/42) ${ }^{6}$.

Tem-se ainda, paralelamente, o processo de descoberta de direitos por parte da comunidade, e as fronteiras, porosas, e as situações, marcadas por conflito, engendram uma mudança de consistência. O arranjo interno do grupo passa por transformações, orientadas no sentido político e pautada em uma reformulação referente à memória e tradições.

As fronteiras entre quem é e quem não é da comunidade, quase sempre muito porosas, passam a ganhar rigidez e novos critérios de distinção, genealogias e parentescos horizontais passam a ser recuperados como formas de comprovação da inclusão ou não de indivíduos na coletividade. Ao mesmo tempo, a maior visibilidade do grupo Ihe dá uma nova posição em face do jogo político. Enfim, a adoção de remanescentes por uma determinada coletividade é, com muito mais força, a produção dessa própria realidade (ARRUTI, 1997: 23).

Portanto, situações históricas peculiares acabam por realçar determinados traços culturais, tal é o caso da identidade quilombola engendrada pela Artigo 68, constituída a partir da possibilidade de direito à terra e instrumento de luta. Verifica-se, como fora anteriormente citado, a criação de novos sujeitos - jurídicos, políticos e sociais.

\footnotetext{
${ }^{6}$ A produção de limites e fronteiras se dá entre os membros e os não membros da comunidade. São limites sociais, que gradativamente ganham novos critérios de diferenciação, para incluir ou excluir indivíduos. Já a produção de memória se dá entre o próprio grupo, outrora possuidor de fragmentos dispersos que irão se unir para desempenhar novo papel. Somado a este processo tem-se ainda outro, de reflexão sobre si mesmo e sobre a própria comunidade, sua história, seus mitos, seus rituais, seus valores. A produção de ampla revisão histórica e sociológica é parte do processo, na medida em que faz-se necessário afastar interpretações errôneas quanto à população negra pós escravidão, caracterizações estas marcadas por preconceitos e misticismos. A produção e ampliação hermenêutica jurídica faz-se ainda necessária na medida em que brechas legais podem ser reapropriadas e introduzir novos elementos no debate (ARRUTI, 2003).
} 


\section{perifèria}

Número 15, diciembre 2011

www.periferia.name

\section{Notas sobre Etnicidade}

A teoria desenvolvida por Barth (1969) substitui a concepção estática da identidade étnica por uma concepção dinâmica, pautada na interação de grupos sociais por meio de processos de exclusão e de inclusão que estabelecem limites entre os referidos grupos. Barth propõe-se a uma investigação empírica do caráter das fronteiras étnicas ressaltando que as "fronteiras persistem apesar do fluxo de pessoas que as atravessam", ou seja, distinções de categorias étnicas independem da ausência de mobilidade, de contato ou de informação, embora acarretem processos sociais de exclusão e de incorporação pelos quais categorias são mantidas, apesar de transformações na participação e pertença no decorrer de histórias individuais. Tem-se ainda que as relações sociais são estáveis e persistentes, mantidas através dessas fronteiras, freqüentemente baseadas em estatutos étnicos dicotomizados.

Grupos étnicos são, segundo essa perspectiva, categorias de atribuição e identificação realizadas pelos próprios atores, e assim têm característica de organizar a interação entre as pessoas. Sendo assim, figura um campo de comunicação e de interação, possuindo um grupo de membros que se identifica e é identificado por outros como se constituísse uma categoria diferenciável de outras categorias de mesmo tipo. É nesse sentido que Manuela Carneiro da Cunha (1986) argumenta sobre a identificação étnica pressupor sinais diacríticos, estes que são selecionados a partir do reservatório representado pela tradição cultural. Buscamse os sinais de acordo com as necessidades dos meios, e estes traços culturais serão isolados do todo que o engloba. Dessa maneira, a tradição cultural é manipulada para novos fins, e não figura como uma instância determinante, uma vez que os grupos étnicos farão uso do arsenal cultural não para conservá-lo, e sim para selecionar o que será diacrítico de pertencimento. É a escolha de alguns traços culturais dentre tantos, que serão a garantia da distinção, em um poço, um 


\section{perifèria}

Número 15, diciembre 2011

www.periferia.name

repositório da cultura ${ }^{7}$. Ainda seguindo a argumentação da autora, sendo a identidade forma de organização política, ela existe em meio mais amplo, este que fornece quadros e categorias, e que explica o exacerbamento em situação de contato. E no que diz respeito à cultura de um grupo étnico, se tem que ela não se perde ou se funde, mas ganha uma função e se torna cultura de contraste, que vai por sua vez determinar outros processos.

Portanto, não se definem grupos étnicos a partir de sua cultura, embora a cultura seja essencial na etnicidade, segue-se o que fora posto por Barth (1969), no que define em termos de adscrição: quem se considera e é considerado. Decorre, para Cunha (1986), que a cultura não é algo dado ou posto, e sim algo constantemente reinventado, recomposto, e ressignificado; de onde decorrem processos - símbolos e signos são selecionados para promover significação nova e rearranjos. A construção da identidade étnica extrai elementos do sistema geral para servirem como diacríticos excludentes - extrai elementos da tradição, que são inteligíveis a todos e são comparados entre si marcando a distinção. Elementos estes que fora do todo onde foram criados ganham novos significados e alteram sentidos, que transbordam o contexto original. Daí decorre a noção de cultura enquanto substrato para a etnicidade, considerando que os traços escolhidos irão depender das categorias comparáveis disponíveis na sociedade mais ampla, que se contrapõem entre si em um sistema, e de onde vem a idéia de acervo cultural. Portanto, a cultura não é pressuposto dos grupos étnicos, e sim produto deles, e a etnicidade é melhor compreendida quando tomada em situação, e como forma de organização política. Será então categoria usada por agentes sociais para os quais é relevante, sendo forma de reivindicação cultural e de protesto político (CUNHA, 1986).

\footnotetext{
${ }^{7}$ A distinção vai ainda depender de outros grupos presentes e da sociedade onde se inserem, uma vez que os sinais diacríticos se opõem a outros de mesmo tipo, figurando assim uma linguagem para pensar diferenças. Portanto, a escolha vai seguir determinantes e se utilizar do que é operativo (CUNHA, 1986). Decorrem três pontos analíticos do uso da etnicidade em sociedade multi étnicas, a saber: um mesmo grupo poder usar identidades diferentes dependendo do interesse específico; a estrutura interna do grupo específico tende a refletir estruturas que definem outros grupos com os quais se relaciona - a estrutura é compartilhada, os símbolos diferenciam; e que para diferenciar grupos é preciso dispor de símbolos inteligíveis a todos os grupos que compõem o sistema em interação. Tem então o caráter reflexivo, situacional e contrastivo das identidades.
} 


\section{perifèria}

Número 15, diciembre 2011

www.periferia.name

Em suma, os grupos são tomados como formas de organização social em populações cujos membros se identificam e são identificados como pertencentes, constituindo uma categoria distinta dentre categorias de mesma ordem. Grupos étnicos distinguem-se de outros grupos - religiosos, de parentesco, etc. - na medida em que se entendem a si mesmo e são percebidos pelos outros como contínuos ao longo da historia, provindos de mesma ascendência, e entendem-se como portadores de uma cultura que os diferencia dos demais (POUTIGNAT \& STREIFF-FENART, 1997).

O foco centra-se nas fronteiras sociais dos grupos, e não na cultura que estas encerram, considerando ainda que a passagem pelas fronteiras não dilui a sua rigidez nem tampouco a existência do grupo. Sendo assim, a identidade étnica de um grupo se dá exclusivamente em função da auto identificação e da identificação pela sociedade englobante. "Além disso, a fronteira étnica canaliza a vida social ela acarreta de um modo freqüente uma organização muito complexa das relações sociais e comportamentais" (BARTH, 1969: 196).

As fronteiras são mantidas entre as unidades étnicas, e a natureza da continuidade e persistência das diferenças culturais podem ser especificadas, assim as fronteiras étnicas são mantidas por "um conjunto imitado de traços culturais". Desse modo, a persistência da unidade depende da persistência das diferenças culturais e a continuidade é especificada por meio das "mudanças da unidade resultantes das mudanças nas diferenças culturais definidoras da fronteira" (BARTH, 1969: 226). Vale ressaltar que a fronteira étnica não restringe a substância cultural que é associada a uma população humana, na medida em que:

os elementos da cultura presente de um grupo étnico não surgem do conjunto particular que constitui a cultura do grupo em um período anterior, embora o grupo tenha existência organizacional continua, com fronteiras (critérios de pertença) que, apesar das modificações, nunca deixaram de delimitar uma unidade contínua (BARTH, 1969: 227).

Os critérios de pertença na interação social, em relação com a questão da identidade coletiva, e, por conseguinte, a questão específica da etnicidade, voltamse à problemática da fixação de símbolos identitários que estruturam a crença em 


\section{perifèria}

Número 15, diciembre 2011

www.periferia.name

uma origem comum. Nesse contexto, Poutignat e Streiff-Fenart (1997) defendem que o diferencial da identidade étnica frente às outras formas de identidade coletiva é a orientação da mesma ao passado, no qual se representa a memória coletiva, uma história mítica, com significações imaginárias sociais que dão, por sua vez, sentido à organização e interações sociais.

Tomando o conceito de grupo étnico, substituindo raça por etnicidade, a definição de remanescente de quilombo deixa de ser calcada em critérios subjetivos, tais como descendência ou cor da pele, e contextuais, estes que refletem racismo e exclusão. Essa noção de grupo étnico associa-se à idéia de afirmação de identidade quilombola, sintetizada pela noção de auto atribuição. Nesse sentido abandona-se o naturalismo que vem com a noção de raça, e deixa de lado o forte historicismo; o que se vê é uma mudança nos valores socialmente atribuídos, e tomando o termo etnia vai-se a critérios organizativos, que apontam às tendências de identificação, reconhecimento e inclusão (ARRUTI, 2003: 29/30). Portanto, passa-se do racial ao étnico, e passa-se da exclusão à inclusão e solidariedade; fazendo disso instrumento político para reivindicações ${ }^{8}$; ou seja, a etnicidade passa a apresentar, juntamente com sua função teórica, uma função política, na mesma medida que a noção de remanescente dá existência política. Desse modo, não só o conceito de quilombo passa por ressemantização, como também o conceito de etnicidade, que se volta à uma propriedade subjetiva dos indivíduos, a um tipo de sentimento.

\section{Orientações Políticas das Identidades}

Diante do exposto, pode-se remeter a Gilroy (1995) no que concerne ao Atlântico Negro, entendido enquanto formação política e cultural. Tal como colocado por Costa (2006), essa noção refere-se à busca do entendimento da participação dos negros no interior de esferas públicas e sociedades civis nacionais, em um paradoxo que é verificado por Gilroy: um marco político por um lado, mas que

8 "o uso da noção de etnicidade é, portanto, inseparável da de etnogênese". (ARRUTI, 2003:30). 


\section{perifèria}

Número 15, diciembre 2011

www.periferia.name

evidencia problemas, uma vez que se reflete nos dois códigos políticos que travam relações tensas no âmbito do Atlântico Negro, no que tange à política da satisfação de necessidades e a política da transfiguração:

A primeira forma [a política da satisfação de necessidades] aceita as regras do jogo político institucional, buscando pragmaticamente fazer cumprir as promessas de inclusão e tratamento igualitário a todos os grupos, acima de adscrições racistas. A política da transfiguração opera com o registro da imaginação utópica, se alimenta nos rituais de confraternização e solidariedade e não é traduzível nos termos da política institucional (COSTA, 2006: 118).

Gilroy (1995) dá conotação político normativa ao termo, no sentido empírico descritivo que remete ao processo de difusão e reconstrução de uma cultura negra que acompanha o movimento da diáspora africana. Desse modo, tal como posto por Costa (2006), a noção de Gilroy não é definida simbolicamente pela referência a determinada origem comum, e sim diz respeito ao compartilhamento de experiências, de um vocabulário ou discurso que permite destilar os traços de semelhança no conjunto diverso de situações concretas ${ }^{9}$. Decorre que não se trata de um contradiscurso, e sim de uma contracultura inserida na modernidade, esta que não é tomada como repertório de manifestações culturais somente, mas deve ser vista de acordo com suas associações políticas, enquanto discurso filosófico que reinterpreta e reconta a história sob a ótica daqueles que estiveram fora das narrativas nacionais. Verifica-se uma reconstrução simbólica, com transformações na dinâmica política:

Os novos modos de identificação cultural e organização política que emergem nacionalmente não seriam imagináveis sem o estreitamento dos vínculos e dos intercâmbios políticos e simbólicos com o espaço imaginado do Atlântico Negro. (...) Neste sentido, essas novas formas de articulação

\footnotetext{
${ }^{9}$ Não será discutida na presente proposta a noção de diáspora, porém vale ser posto que o Atlântico Negro de Gilroy (1995) faz referência à expressão cultural da diáspora africana, o que segundo Costa (2006) desafia as concepções puristas de identidade e cultura enquanto atemporais e estáticas. Citando Gilroy (1995:23): "A identidade tem que ser demonstrada em relação a possibilidade alternativa de diferenciação, visto que a lógica da diáspora impõe o sentido de temporalidade e espacialidade o qual ressalta o fato de que nós não somos o que nós fomos".
} 


\section{perifèria}

Número 15, diciembre 2011

www.periferia.name

cultural podem ser tratadas como processos de construção de novas etnicidades, já que apresentam o caráter móvel, descentrado e múltiplo destacado por Stuart Hall (COSTA, 2006: 149).

Pode-se aproximar à problematização ao do processo de auto constituição de comunidades remanescentes de quilombo como grupos culturais e sociais diferenciados; remete-se à etnogênese, aproxima então a questão à noção de etnicidade. A ruptura proposta por Barth (1969) é relevante nesse sentido, pois evita confusões dadas quando converte-se a abordagem de etnicidade na perspectiva da raça. assim, tem-se a preocupação em distinguir o conceito de grupo étnico de qualquer significado cultural inerente,

para vê-lo como uma entidade social que emerge da diferenciação estrutural dos grupos em interação, um modo de construir oposições e classificar pessoas, em que o social e simbolicamente relevantes são as fronteiras desses grupos - o que em uma primeira formulação era apresentado como 'o problema dos limites do grupo político (cf. Fortes e Evans-Pritchard 1981 [1940]) - e os mecanismos de criar e manter tais fronteiras (ARRUTI, 1997: 26).

No tocante à noção de etnogênese, tem-se a relação desta com a 'invenção cultural', tomada em sentido positivo, que contribui para dar importância normativa, afetiva e valorativa às identidades, criando as condições de possibilidade para o surgimento de um sentimento de unidade e pertencimento, bem como de destinos comuns, para que surja assim uma 'comunidade imaginada' entre os membros do grupo (OLIVEIRA FILHO, 1993) ${ }^{10}$. Assim se chega às considerações acerca da etnicidade, tomada como forma de organização social, pautada na atribuição categorial classificatória de indivíduos em função de sua

\footnotetext{
${ }^{10}$ Acerca das comunidades de quilombos: "Devemos reconhecer a relação dialética que se estabelece entre o herdado e o projetado, entre passado e o futuro que, no curso das interações, submete elementos de cultura, de estrutura e de memória a re-significações e re-atuações. $A$ constatação das permanências, dos sincretismo e das contrastividades não serve mais como resposta, mas como ponto de partida" E prossegue, ressaltando que deve-se "reconhecer sua construtividade ligada à 'plasticidade identitária' que marca boa parte dessas comunidades" (ARRUTI, 1997: 29-30).
} 


\section{perifèria}

Número 15, diciembre 2011

www.periferia.name

origem suposta, esta "validada na interação social pela ativação de signos culturais socialmente diferenciadores" (POUTIGNAT \& STREIFF-FENART, 1997: 141).

Tal como posto por Sansone (2007:10), a etnicidade tornou-se tema conhecido nos dias atuais, com ampla abrangência:

étnico passou a substituir termos como exótico, estranho, não branco, ou em linguagem simples, raro e diferente. Essas tendências na maneira como a cultura popular tem-se havido com a diversidade étnica e racial fazem parte de uma mudança maior e momentosa

No que tange a etnicidade ser tomada como o 'diferente', se pode remeter ao reconhecimento dos direitos de minorias étnicas, tal como toma o próprio Estado e contempla na Constituição. Já passado o período da 'integração', reconhece-se o direito a diferença e o respeito à auto adscrição, e daí se dão as possibilidades de mobilização política em torno da identidade étnica. Sansone (2007: 29/30) aponta mudanças ocorridas nas ultimas décadas do século XX na América Latina, dentre as quais podem-se destacar os avanços políticos que viabilizaram a possibilidade de reconhecimento dos direitos étnicos ${ }^{11}$ : "nessa etapa mais nova das relações interétnicas, o multiculturalismo é celebrado pelo Estado e por outros agentes".

Uma série de fenômenos recentes marcam o que diz respeito à cultura e à identidade negras: "hoje mais do que nunca identificar-se como negro é participar da dinâmica sócio política brasileira e dos acontecimento internacionais que cercam o Atlântico Negro" (SANSONE, 2007: 295). É nesse sentido que Costa (2006: 133) também mostra as mudanças ocorridas no país que "fizeram com que a nação

\footnotetext{
11 Tal como ocorrera no Brasil a partir da Constituição de 1988, outros países também empenharam mudanças nesses sentido em suas cartas constitucionais, tal como a Colômbia, a Bolívia e a Nicarágua. É o momento em que se passa do indigenismo, voltado à 'proteção dos povos', para o indianismo, dar voz aos povos.
} 


\section{perifèria}

Número 15, diciembre 2011

www.periferia.name

brasileira, monocultural na sua festejada mesticidade, se transformasse numa sociedade extremamente plural e diversa"12.

Todavia, antes do termo multiculturalismo ganhar projeção e passar a ser pensado como concretamente possível, a integração cultural era a palavra de ordem às minorias étnicas. Passa-se então ao respeito às diferenças e ao reconhecimento oficial das mesmas, junto com a idéia de que as tais minorias devem tomar a direção do que Ihes diz respeito ${ }^{13}$. Contudo, uma nova problemática é apontada:

hoje em dia, há na base de muitas teorias multiculturalistas uma nova supersimplificação e reificação da idéia de cultura, mediante a qual a manutenção da diferença é sine qua non da mobilidade ascendente. Nesse aspectos as varias minorias étnicas (...) comumente representam o grupo ideal (SANSONE, 2007: 257).

A mobilização política da etnicidade, portanto, alicerça a luta por direitos; contudo, não se pode tomar os grupos étnicos como imutáveis. Vale ser considerada a tendência que têm os procedimentos jurídicos e administrativos de imobilizar fronteiras, ao fixá-las em modelos pré-estabelecidos, de modo a, por vezes, não coincidirem com a experiência vivenciada pela comunidade. O próprio artigo, ou a legislação de um modo mais geral, criam novas fronteiras e condições para que a identidade étnica se desenvolva, bem como influencia as estratégias baseadas na etnicidade. E tal como posto por Sansone (2007: 15) "parecemos estar nos deslocando para novos conflitos, menos transparentes e menos românticos. Não obstante, os conflitos costumam ser apresentados e interpretados com base num termo abrangente simples: etnicidade".

\footnotetext{
12 As discussões se deram em torno da cidadania na Constituinte, incluindo nessa idéia as dimensões política e cultural. Criminalizou-se o racismo na esteira da busca pela igualdade legal, institucionalizouse mecanismos que permitem o reconhecimento de manifestações culturais afro brasileiras.

${ }^{13}$ Vale ser mencionada essa transformação a partir das convenções internacionais que dizem respeito aos direitos de minorias. A Convenção no 107 da OIT, de 1957, já tratava especificamente de populações indígenas e tribais, representou uma primeira tentativa de codificar em um instrumento legal de âmbito internacional, os direitos fundamentais desses povos. passou a ser criticada por suas tendências integracionistas e paternalistas, e em 1986 foi considerada obsoleta pelo Comitê e sua aplicação tida enquanto não compatível com o mundo moderno. As propostas para sua revisão vieram a dar origem a Convenção no 169, com vistas à ativa e efetiva participação no planejamento e execução de projetos que dissessem respeito a estes povos.
} 


\section{perifèria}

Número 15, diciembre 2011

www.periferia.name

Vale colocar a ressalva feita quanto ao perigo de essencializar a diferença e dar aparência de ser estática, pois é um processo ${ }^{14}$. Outro ponto importante a ser lembrado diz respeito ao fato de identidades negras estarem em relações que são locais - sistemas locais de relações raciais - e também globais, por semelhanças históricas internacionais derivadas da experiência da escravidão (SANSONE, 2007). E na política da identidade, a sua afirmação tem poder: "(...) num mundo que vem se tornando cada vez mais entremesclado em termos étnicos e culturais, a política da identidade caminha pari passu com a política do multiculturalismo" (SANSONE, 2007: 17). Dessa forma, a etnicidade figura apenas enquanto um dos componentes da complexa discussão.

A identidade negra será, como todas as etnicidades, relacional e contingente: "a identidade étnica se constrói em relação a outras identidades sociais, e é sempre dada e conquistada no sentido de que a visão das pessoas de fora co-determina as maneiras pelas quais um grupo étnico se (re) descobre" (SANSONE, 2007: 255). Assim se dá orientação política à luta por direitos. A contrapartida, esperada pelas agências envolvidas no processo de reconhecimento, é que as comunidades exibam certos traços, e reelaboram uma identidade que se adéqüe à moldura formal, uma vez que as relações se manifestam dentro de um quadro mais amplo, figurado pelo Estado, através das distintas vozes que são parte do processo de reconhecimento, com procedimentos e normativas que são peculiares a cada uma dessas agencias e suas atribuições.

O Estado é esta totalidade que transcende e integra os elementos concretos da realidade social, ele delimita o quadro da construção da identidade. É através de uma relação política que se constitui assim a identidade: como construção de segunda ordem ela se estrutura no jogo da interação entre o nacional e o popular, tendo como suporte real a sociedade global como um todo (ORTIZ, 2006: 138/139).

\footnotetext{
${ }^{14}$ Nesse sentido, Sansone (2007: 300) distingue cultura negra como referente a traços comuns na
} produção cultural das populações negras, ao passo que culturas negras diz respeito às variantes locais. 


\section{perifèria}

Número 15, diciembre 2011

www.periferia.name

O contexto é mais amplo do que a própria redefinição da identidade, há todo um movimento que circula e oscila entre instâncias marcadas pelo genérico, por um lado, e pelo singular por outro. Ao mesmo tempo que a luta é travada dentro do Estado, uma luta por direitos que tem respaldo constitucional, há uma luta empenhada fora dele, na própria comunidade, e em seus interstícios, uma vez que há relações com outros grupos e a sociedade envolvente. Ortiz (2006: 141) toma à sua análise a construção da identidade nacional, cujos mediadores seriam os intelectuais, responsáveis por descolar manifestações culturais da esfera particular - popular - e articulá-las a uma totalidade que as transcende. O que serve à presente reflexão: "Um exemplo deste tipo de articulação se encontra na elaboração da identidade étnica - neste caso a totalidade coincide com a etnia e não mais com a nação". É nessa perspectiva que os movimentos negros são vistos como operar de modo análogo, buscam formas concretas de expressões culturais para integrá-las e reinterpretá-las dentro de uma perspectiva mais ampla. Nesse sentido, no caso dos movimentos negros brasileiros, a cultura afro brasileira não é simplesmente vivenciada na sua particularidade, mas o singular passa a definir uma instancia mais generalizada de conhecimento. Ao integrar em um todo coerente as peças fragmentadas da historia africana (negra) - candomblé, quilombos, capoeira - os intelectuais constroem uma identidade negra que unifica os atores (ORTIZ, 2006: 141).

O que Costa (2006) mostra pelas conexões dos movimentos negros, importantes ao debate proposto, é que no Brasil desempenharam importante papel na esfera pública no período da redemocratização - influindo inclusive no desenvolvimento do que veio a ser o Artigo 68 durante os trabalhos na Constituinte ${ }^{15}$ - com uma rede transnacional. Volta-se então à amplitude dessa rede anti racista, a partir da análise da complexa articulação de discursos no âmbito nacional e transnacional, fazendo uso da Sociologia da Cultura para apreender as tensões travadas entre diferentes modelos de relações étnicas existentes nos distintos contextos da rede

15 Essa reflexão foi desenvolvida no artigo $O$ Processo de Fortalecimento do Ministério Público na ANC/1987 e sua atuação no Artigo 68 do ADCT/CF-88 (FERREIRA, 2009). 


\section{perifèria}

Número 15, diciembre 2011

www.periferia.name

anti racista. Assim mostra os vínculos entre os discursos anti racistas brasileiros e as construções que se dão no âmbito do Atlântico Negro.

A ênfase recai nas novas etnicidades, cuja discussão é internacional no âmbito das políticas, porém sua implementação é nacional. Considerando ser no âmbito as relações cotidianas que padrões identitários são negociados e apropriados, das mais distintas formas, o que se tem são identidades negras construídas no âmbito local (COSTA, 2006). Aqui novamente se pode remeter à generalidade da legislação, que pode se opor às singularidades de cada construção identitária, de modo que isso possa até mesmo influir negativamente no reconhecimento dos direitos em questão.

Pode-se então pensar o caso da identidade quilombola sob essa mesma ótica, uma vez que é construção, e toma formas diversas na realidade das comunidades em questão, e pode não coincidir com a memória particular desses grupos. Ortiz (2006: 139) prossegue: "o discurso nacional pressupõe necessariamente valores populares e nacionais concretos, mas para integrá-los em uma totalidade mais ampla". Seria semelhante ao que faz a legislação quando espera traços e manifestações concretas da identidade quilombola para que tenham seus direitos efetivamente assegurados, daí a necessidade de relatórios técnicos e laudos de reconhecimento (FERREIRA, 2010).

\section{Considerações Finais}

O que se vê a partir do caso dos remanescentes de quilombos no Brasil é exemplo de um processo maior, que assume formas distintas nos diversos países, quando grupos mobilizam a etnicidade para acessar direitos que são constitucionalmente assegurados. Vê-se aqui a relação onde a lei cria seus sujeitos, que vão além do próprio direito em questão. O Artigo 68 diz respeito a um direito fundiário em sua redação, todavia, no momento que institui o sujeito 'remanescente de quilombo' dá margem a uma série de outros intrincados direitos, impactando em políticas públicas e ações afirmativas. Isso posto, voltou-se a atenção à orientação política da etnicidade, tal como sugere Sansone (2007: 256/257) quando propõe examinar 


\section{perifèria}

Número 15, diciembre 2011

www.periferia.name

a identidade étnica tal como faríamos com a ideologia religiosa ou tendências políticas dependem do contexto. (...) Essa variabilidade política vai de encontro a muitas das generalizações postuladas pelas teorias multiculturalistas da cultura (Kuper, 1999) no que concerne às culturas e identidades negras.

A auto definição enquanto quilombola coloca em questão um novo tipo de identidade negra, de cultura negra. Vai-se além do quilombo da fuga e da resistência, e além do próprio confronto, uma vez que a situação dessas comunidades, embora permeadas por conflitos, é agora de sujeito político e de direito. O movimento quilombola brasileiro que se consolidara na ultima década mostra o lugar social que os grupos vem ocupando, embora se observem retrocessos administrativos e jurídicos. E a cultura negra que se faz presente no fenômeno do reconhecimento, somada às culturas negras que cada comunidade apresenta, mostram a dinâmica do 'processo cultural negro', este que pode ser visto pela linguagem da reivindicação, pelo aparato que é manipulado para acionar o Artigo 68. Reivindicam seus direitos proclamando-se não somente negros, mas sim quilombolas ${ }^{16}$. Aqui a cor da pele já não tem mais o mesmo peso que fora posto por Sansone (2007), embora seja relevante; não é a auto definição da cor que definirá o grupo e sua posição social e cultural específicas. E assim se passa da invisibilidade dos negros à prerrogativa constitucional dos quilombolas.

Tentou-se então pensar a partir do caso dos remanescentes de comunidades de quilombos acerca das políticas da identidade e da cultura, onde figuram como agentes tanto o Estado e seu aparato legal como a própria comunidade, instituída enquanto sujeito, que politiza suas etnicidades no processo. Por isso, defende-se que a identidade passa a figurar tanto como elemento de unificação quanto fundamento para ação política.

\footnotetext{
16 Dessa forma aproxima-se do que Sansone (2007: 153) coloca quanto a nova identidade baiana negra, que enfatiza alguns dos dilemas das relações raciais brasileiras. No caso dos remanescentes, coloca-se em evidência a comunidade negra e a cultura negra ao lado da auto atribuição e do reconhecimento oficial. E verifica-se que "existe o desenvolvimento de uma nova identidade negra, um tipo de orgulho negro".
} 


\section{perifèria}

Número 15, diciembre 2011

www.periferia.name

\section{Referências Bibliográficas}

BRASIL. Constituição da República Federativa do Brasil. Brasília: 1988.

CARTA DE PONTA DAS CANAS. Associação Brasileira de Antropologia e Núcleo de Estudos sobre Identidade e Relações Interétnicas, ABA - NUER/UFSC, 2000. Disponível em www.abant.org.br/conteudo/001DOCUMENTOS/DocumentosABA/cartacanas.pdf; acesso em 02/01/2011.

Convenção no. 169 sobre Povos Indígenas e Tribais em Países Independentes. Organização Internacional do Trabalho, 1989. Disponível em http://www.oitbrasil.org.br/info/downloadfile.php?fileId=131, acesso em 05/01/2011.

ALMEIDA, Alfredo W. B de. Quilombos: sematologia face a novas identidades. In Frechal Terra de Preto: Quilombo reconhecido como Reserva Extrativista. São Luís: SMDDH/CCN-PVN, 1997.

ALMEIDA, Alfredo Wagner B. \& PEREIRA, Deborah Duprat de B. As Populações Remanescentes de Quilombos - Direitos do Passado ou Garantia para o Futuro? Seminário Internacional "As minorias e o Direito", 2003.

ARRUTI, José Maurício. A Emergência dos 'Remanescentes': notas para o dialogo entre indígenas e quilombolas. In: MANA 3(2), 1997. O quilombo conceitual: para uma sociologia do artigo 68 do ADCT. Texto para discussão: Projeto Egbé - Territórios negros (KOINONIA), 2003. - Mocambo: Antropologia e história do processo de formação quilombola. Bauru, SP: Edusc, 2006.

BARTH, Fredrik. Los Grupos Etnicos y sus Fronteras. Mexico. Fondo de Cultura y Economia, 1969.

COSTA, Sérgio. Dois Atlânticos. Teoria Sociais, Anti-Racismo, Cosmopolitismo. Belo Horizonte: Editora UFMG, 2006.

CUNHA, Manoela Carneiro. Antropologia do Brasil: mito, história, etnicidade. São 


\section{perifèria}

Número 15, diciembre 2011

www.periferia.name

Paulo: Brasiliense \& EDUSP, 1986.

LAPIERRE, Jean William. Introdução às teorias da etnicidade. In POUTIGNAT, P. \& STREIFF-FENART, J. Teorias da Etnicidade. São Paulo: Fundação Editorial da UNESP, 1997.

MINTZ, Sidney W. \& PRICE, Richard. O Nascimento da Cultura Afro-Americana: uma perspectiva antropológica. Rio de Janeiro: Pallas: Universidade Candido Mendes, 2003.

ORTIZ, Renato. Cultura Brasileira e Identidade Nacional. São Paulo: Brasiliense, 2006.

POUTIGNAT, Philippe \& STREIFF-FENART, Jocelyne. Teorias da Etnicidade. São Paulo: UNESP, 1997.

SANSONE, Lívio. Negritude sem Etnicidade. O Local e o Global nas Relações Raciais e na Produção Cultural Negra do Brasil. Salvador/ Rio de Janeiro: EDUFBA/ Pallas, 2007.

SCHMITT, Alessandra; TURATTI, Maria Cecília \& CARVALHO, Maria Celina. A Atualização do Conceito de Quilombo: identidade e território nas definições teóricas. Comunicação de Resultados/ Research Results, Ambiente e Sociedade, ano $\mathrm{V}, \mathrm{n} \circ 10,1 \circ$ semestre de 2002.

STUCCHI, Deborah. Percursos em dupla jornada: o papel da perícia antropológica e dos antropólogos nas políticas de reconhecimento de direitos. Tese (doutorado) Universidade Estadual de Campinas, Instituto de Filosofia e Ciências Humanas, 2005.

TRECCANI, Girolamo. Terras de Quilombo: caminhos e entraves do processo de titulação. Belém: Programa Raízes, 2006.

VALE DE ALMEIDA, Miguel. Ser mas não ser, eis a questão. O problema persistente do essencialismo estratégico. Paper apresentado na Sessão Lógicas do Poder, Congresso da Associação Portuguesa de Antropologia, Lisboa, 2009. 